\title{
The Effect of Payment System Environment on Purchase Intention: An Empirical Study on Fliggy
}

\author{
Ranzhe Jing and Zijie Lu \\ School of Information Management and Engineering, Shanghai University of Finance and \\ Economics, 200433 Shanghai, China \\ jing.ranzhe@sufe.edu.cn, 1292j@sina.com
}

Keywords: E-commerce, payment system environment, transaction process, purchase intention.

\begin{abstract}
Nowadays the e-commerce paradigm has prevailed all over the world, definitely changing the way of running businesses and shaping the new business environment. The web-based business solutions have produced a novel type of a consumer, the online consumer, and a specific way of doing business at Internet, based upon the human-computer-web interaction. The behavior of the online consumer has proven to be a key not only to a successfulness of a given online commerce site, but also to obtain a significant knowledge about customer's habits, needs, expectations, etc. Nonetheless, the online consumer behavior can also be used as a basis for obtaining the basic web performance metrics, necessary for assuring a relevant level of online payment system environment through online transaction process. This research aims to highlight some of the most important aspects of modeling consumer online behavior regarding web performance. It proposes a novel approach to modeling online purchase intention, based on usage of online payment system environment.
\end{abstract}

\section{Introduction}

Amazingly rapid development of Internet has brought the boom in e-commerce application. The contemporary running of businesses means extensive usage of web-based technologies and e-commerce solutions built upon the online paradigm. This global phenomenon includes all modalities of Web-based trading and shopping, where all activities between the two parties involved are carried out online via Internet [1].

Online payment system is one of the most influential sources of information on the web. Online payment is developing rapidly in many countries, for years, this has developed into a new niche market, the online payment market, offering an optimal opportunity for the e-commerce industry to diversify its services. Online payment process of combining products and services from the e-commerce industry and the financial industry together [2].

The purpose of this research is to provide the fundamental analytic techniques, methods, and model to understand the behavior of e-commerce systems and the online customers. It introduces concept and model associated with the effect of payment system environment on purchase intention.

\section{Transaction Process and Online Payment System Environment}

Generally speaking, the process of e-commerce transaction process includes: entry, welcome, find a product, register, place an order, as shown in Fig. 1.

The Find a Product step can be accomplished by two main functions, namely Search and Browse. A third way to select a product is to pick up one of the hot items, which are displayed in the special offer section, located in the Welcome page. To place an order, a consumer has to select the product using the Add to Shopping Cart function. Before checking-out, the customer must have gone through the registration process, which sets up an account and provides the customer identification and password. The platform uses secure connections for transactions that transmit confidential information. To check out, the customer simply clicks on the Check-Out button to submit the order for the items in the shopping cart. During the check-out process, the platform contacts the billing 
service, which checks with the buyer's bank or credit card company or the third-party payment platform to obtain the credit authorization. Then the billing service informs the platform that the transaction is approved and the product delivery process is started. The transaction completes when the customer receives the products purchased. From the customer's perspective, the site is easy to use and efficient. With three clicks, a registered customer is able to perform all the steps required by the purchase process, from product selection to check-out. The site has usually also a privacy policy clearly stated in the Welcome page [3] [4].

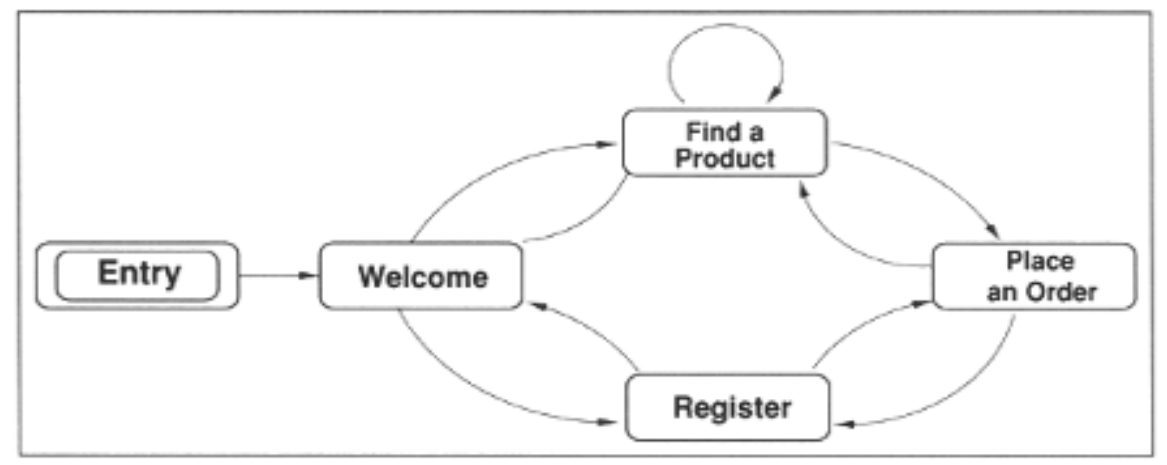

Fig.1. The process of e-commerce transaction process

To achieve the level of revenue set by the business plans, the online platform has to attract more visitors and to increase the number of visitors that buy something.

Fliggy is an OTA(Online Travel Agent), which integrated travel service platform, designed to provide users with convenient, cost-effective travel services.

Alipay supports online payments, it is a third-party mobile and online payment platform, This function enables Alipay users to make purchases on websites and in merchants' apps with Alipay. During the purchases, Alipay is able to deduct the amount of payment from the users' Alipay account in Chinese yuan and send the payment to the merchants in different foreign currencies. Alipay requires Chinese business license when applying for Alipay for business, therefore foreign companies without established legal entity in China cannot use Alipay business account. However third party payment solution providers can provide such services [5] [6].

Alipay provides an escrow service, in which consumers can verify whether they are happy with goods they have bought before releasing money to the seller. This service is offered for what the company says are the weak consumer protection laws, which have reduced consumer confidence in C2C and even B2C quality control.

By using Alipay, transfers can be made from one Alipay online account to another account or from the online account to a bank account (via a debit card). The user can transfer money online without face to face delivering. The transfer link can also be found in "my applications", and it is free for the transfer between two accounts. Using the Alipay to transfer money into a bank account is cheaper and faster than making the transfer at the bank counter.

The users can save the money in the Alipay and receive some revenue on a regular basis. There is an option called "Yuebao" in Alipay, which is the project that cooperate with "Tianhong Fund", which is responsible for the financial management. The user can save money in "Yuebao" and use those money to pay, transfer or withdraw in the same day, meanwhile, people can get a small part of proceeds on a daily basis which in terms of the amount of saving money. As for the fund company, the enterprise can receive a lot of financial resources through Alipay, expanding the scale of business and attracting a large number of network customers. The Alipay can get some allowance from the fund company and also let the people rely more on the use of Alipay.

In the fourth quarter of 2016, Alipay had a 54\% share of China's US $\$ 5.5$ trillion mobile payment market, by far the largest in the world, although its share fell from $71 \%$ in 2015 as its rival Tencent's WeChat Pay was rapidly catching up. As of September 2017, Alipay unveiled a 
facial recognition payment service.

Alipay provides multiple security mechanisms to make sure that user accounts are safe. At the same time, Alipay also has a binding mobile phone security measure. When the customer is using Alipay to make a transaction, they will receive a notification that their Alipay account is being used, so the user can know whether it is their own operation.

Alipay real name certification is a kind of identification service, which can help check the identity of the buyer and seller, and their bank account information. Alipay also installs a digital certificate, which can encrypt information sent over a network, preventing hackers from stealing passwords, thereby enhancing the security of online transactions.

Mobile payment is being adopted all over the world in different ways. A simple mobile web payment system can also include a credit card payment flow allowing a consumer to enter their card details to make purchases. This process is familiar but any entry of details on a mobile phone is known to reduce the success rate of payments. In addition, if the payment vendor can automatically and securely identify customers then card details can be recalled for future purchases turning credit card payments into simple single click-to-buy giving higher conversion rates for additional purchases.

\section{Discussions}

Third party payment process must be supervised by NUCC (Nets Union Clearing Corporation) now, it is also called as collaboration model, this model involves collaboration among banks, mobile operators and a trusted third party.

Show as Fig.2, Managers always want to get the best website revenue, at the same service level, they maybe want to move the point from $\mathrm{E}$ to $\mathrm{K}$, but at point $\mathrm{K}$, technology support capability that needed is more greater than point $\mathrm{E}$, it means that it must increase investment to improve the function of the platform, it will increase technology support costs obviously, and decreasing the website's revenue ratio in the end, consider the dynamic change of customer quantity and technology support capability, we need a collaborative arithmetic to find which is the best position of revenue, for example at point C [7].

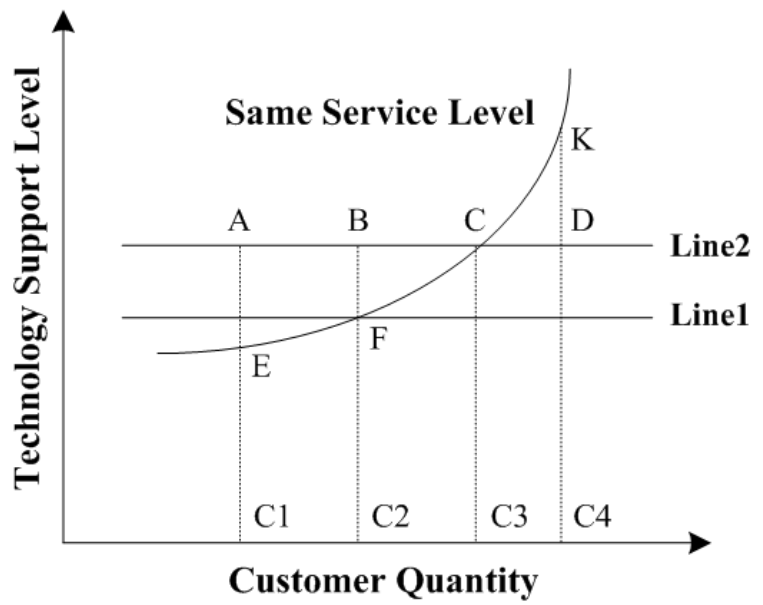

Fig.2. The relationship of services Level and technology support level

Because of the great difference of increasing speed between technology support capability and customer quantity, at the same service level, little improved of technology support capability can support great increasing potential of customer quantity.

Generally speaking, the technology support level lies on the capability of the information technology environment framework, different utilization of online payment system environment brings different capability of technology support, on the other hand, the change of customer quantity is also uncertain, thus, the effect of payment system environment on purchase intention 
should be discussed.

Purchase intention is regularly decided by the services quality, the services quality is ordinarily determined by the online payment system environment [8] [9].

To customer, response time is the most important aspect, so we choose the Service Time as the standard of website's technology support capability, Service Time includes three parts, show as Eq.(1),

\section{ServiceTine $=C D$ Time+ NetworkTine+SD Time}

where, CD_Time denotes the Client Disposal Time, SD_Time denotes the Sites Disposal Time. NetworkTime means the network transport time, Show as Fig.3.

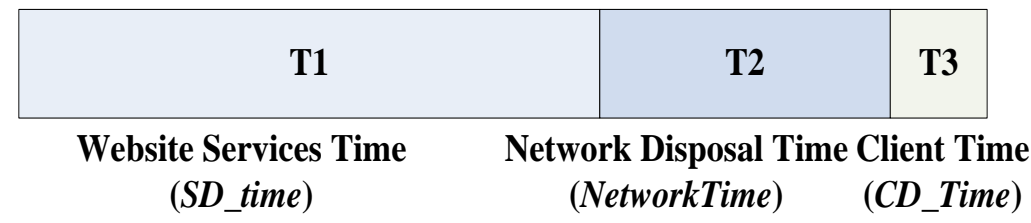

Fig.3. The main parts of service time

Commonly, the proportion of $T_{2}$ and $T_{3}$ is small to the whole service time correspondingly, so we can use the SD_Time as the standard of website service level, if the platform IT system environment does not change, the SD_Time lies on the system's utilization and the combination of customer services request.

Each customer has a base line of a request's response time, for example, 5 seconds, get rid of the parts of $\mathbf{T}_{2}$ and $\mathbf{T}_{3}$, we get the net value demand of $S D \_T i m e$ is equal to $5 T_{1} /\left(T_{1}+T_{2}+T_{3}\right)$.

As the increasing of customer visit quantity, service request increasing rapidly, the utilization of the website's server also increasing quickly, at the same service level (Service Time), the platform's revenue will improving as the customer purchase intention increasing, but its achievement is under the condition of the server's utilization less than one and the response time does not exceed the customer's base line [7].

To maximize the revenue, we propose a model as Model.1 by combining the arithmetic of fuzzy simulation, NN and heredity [10] [11].

We first assume the website's revenue is the function of TCVQ, $B V, R T_{\mathrm{i}}$ and $U_{\mathrm{i}}$, and then via the restriction of utilization and service time to get the value of maximizes revenue.

The whole algorithm proposed for Model.1 consists of the following steps:

(1). Use the technology of fuzzy simulation brings input-output data for the uncertain functions as follow:

$$
\begin{aligned}
& \Phi 1: x \rightarrow \operatorname{Cr}\left\{g_{j}(x, \xi) \leq 0, j=1,2, \cdots, p\right\}, \\
& \Phi 2: x \rightarrow \max \{\bar{R} \mid \operatorname{Cr}\{R(x, \xi) \geq \bar{R}\} \geq 0.95\}
\end{aligned}
$$

(2). Train a NN to approach the uncertain function by the input-output data.

(3). Produce initial pop_size chromosomes, and validate the filial generation chromosomes' feasibility using the trained NN.

(4). Refresh chromosomes by the operation of crossover and variation, and validate the filial generation chromosomes' feasibility using the trained NN.

(5).Calculate all chromosomes' objective value by the trained NN.

(6). Calculate each chromosome's adaptability by the objective value.

(7). Choose chromosome by the totary-game-wheel.

(8). Repeat step 4 to 7, till given circular times.

(9). Using the best chromosome as the optimum answer. 


$$
\left\{\begin{array}{l}
\text { Max } \bar{R} \\
\text { s.t. } \\
\quad \operatorname{Cr}\left\{R\left(T C V Q, B V, R T_{i}, U_{i}, \xi\right) \geq \bar{R}\right\} \geq 0.95 \\
R T_{i} \leq \frac{\mathrm{t}_{0} T_{1}}{T_{1}+T_{2}+T_{3}} \\
\operatorname{TCVQ}=\sum_{\mathrm{i}=1}^{\mathrm{n}} n_{i}=\sum_{\mathrm{i}=1}^{\mathrm{n}} \frac{U_{i}}{1-U_{i}} \\
U_{i} \leq 1 \\
R T_{i} \geq S_{i} \\
R=\frac{\text { Session }}{\text { sec }} \times B V \times \text { AverageSales } \times 3153600 \\
B V \leq 1 \\
\text { AverageSales }=\frac{R}{P C Q} \\
B V=\frac{P C Q}{\text { TCVQ }} \\
\mathrm{t}_{0}=3 \\
i \geq 1, \quad i=1,2,3 \cdots \mathrm{n} .
\end{array}\right.
$$

Model.1. Collaborative arithmetic model

Via the real visit data from Fliggy, we get the fig.4. as follow,

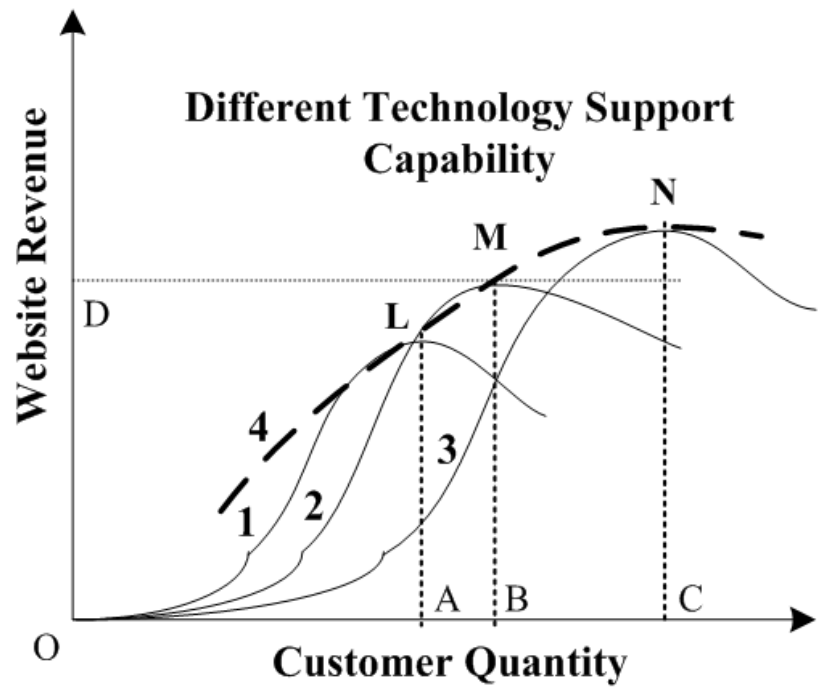

Fig.4. Figure of revenue and customer quantity

Fig.4 shows the relation of revenue and different technology support capability, the top point of curve 1 , curve 2, and curve 3 shows the maximal revenue of technology support capability correspondingly, curve 4 shows the relation of maximal revenue and the technology support capability, to a certain revenue objective, via the curve 4, we can get the optimal customer quantity and the only online payment system environment investment. 


\section{Conclusion}

Based on the analysis of the e-commerce paradigm and its online payment system environment through online transaction process, found the online consumer behavior rules, select fuzzy simulation, $\mathrm{NN}$ and heredity to optimize the value of website revenue. Thus the effect of payment system environment on purchase intention is revealed.

The results suggest that online payment system environment has a significant impact on purchase trust and intention. The role of online payment system environment trust in e-commerce marketing is very important, because online payment system environment trust is believed to be a fundamental component of building successful business relationships, since it has the ability to influence perceptions of confidence, reliability, and integrity among exchange partners. More generally, the enormous pressure on online payment system to increase the attractiveness of their purchase suggests that it is both logic and practical to increase positive online revenue.

\section{Acknowledgement}

In this paper, the research was sponsored the National Natural Science Foundation of China (NSFC Program No.71072037).

\section{References}

[1] Joan L. McNamara. Scaling for e-business: technologies, models, performance, and capacity planning [M]. Prentice-Hall International (UK) Limited, London, 2001. 121-126.

[2] Jonas Hedman, Thomas Kalling. The business model concept: Theoretical underpinnings and empirical illustrations [J]. European Journal of Information Systems, 2003 12(1):49.

[3] K. Nikolaos, P. Marios, Using online consumer reviews as a source for demographic recommendations [J]. Expert Systems with Applications. 2013 (40) 5507-5515.

[4] Amaro Suzanne, Duarte Paulo, Online travel purchasing: A literature review [J]. Journal of Travel \& Tourism Marketing, 2013 (30) 755-785.

[5] Jing R. Online customer value structure: a network analysis approach. In Practical applications of intelligent systems [J]. Berlin Heidelberg: Springer, 2012 (1) 259-264.

[6] Wang, J., and R. Jing. Exploring on the ways to improve online customer loyalty. Paper presented at International Conference on Electronics, Information and Communication Engineering [c]. Taipa Island, Macau, 2012 (3) 21-27.

[7] Devece Carlos, Garcia Sergio, Ribeiro Belén, The Value of Trust for Travel Agencies in Achieving Customers' Attitudinal Loyalty [J]. Journal of Promotion Management, 2015 (21) 516-529.

[8] No. Eunjung, Kim Jin Ki, Comparing the attributes of online tourism information sources [J]. Computers in Human Behavior, 2015 (50) 564-575.

[9] M. Francisco, H. Janet, S. Juan, Generalising user behaviour in online travel sites through the Travel 2.0 website acceptance model [J]. Online Information Review. 2012 (36) 879-902.

[10] Pesonen Juho Antti, Targeting Rural Tourists in the Internet: Comparing Travel Motivation and Activity-Based Segments, Journal of Travel \& Tourism Marketing, 2015 (32) 211-226.

[11] Sabiote Carmen, Jamilena Dolores, Castañeda-García J. Alberto, Overall Perceived Value of a Tourism Service Delivered via Different Media [J]. Journal of Travel Research, 2016 (55) 34-51. 